\title{
Study on Earnings Management Behavior of *ST Companies --- Takes *ST SKGF as an Example
}

\author{
Jihui Sun ${ }^{1, a}$ and Xiufei Liang ${ }^{1, b}$ \\ ${ }^{1}$ School of Economics and Management, Dalian University, Dalian, China \\ adlsunjihui@163.com, b823475346@qq.com
}

Keywords: Earnings management; Delisting risk warning; Turnaround of profit; Picking stars; *ST SKGF

\begin{abstract}
The Company which was carried out delisting risk warning usually uses various means of earnings management to reach the purpose of "shell", because "shell" resources of Chinese public companies are scarce and precious[1][2]. Under such background, this paper investigates the motivation of earnings management of SKGF which faced risk of delisting from the "stars" from three directions, and in-depth analyzes the company's financial data to reveal *ST SKGF how to use asset impairment recovery, related party transactions, and non-recurring profit and loss and other means for earnings management to success to protect shell.
\end{abstract}

\section{Introduction}

A large number of studies have shown that *ST companies will produce strong earnings management motivation if they couldn't improve the operating performance effectively in the short term, and will whitewash financial statements by earnings management means to avoid being suspended [3][4]. Studying behavior of *ST companies' earnings management not only can reveal most of managers adept at using this economic behavior, but also help to establish and improve accounting standards [5]. Relevant departments develop a targeted laws and regulations to maintain the interest of investors and the normal order of securities market operation and to ensure the effective configuration of the resources and reasonable according to the results of the study.

\section{Case Analysis of *ST SKGF}

SKGF founded in 1996, listed on the Shenzhen Stock Exchange in 2011. Due to the poor operating performance, the company had showed deficits for two years' running: the net profit attributable to shareholders of listed companies audited in 2014 and 2013 was -28,540,949.63 and -37,999,954.09 Yuan respectively. According to relevant regulations, SKGF's stock since opened in January 28, 2015 would be implemented the special treatment of delisting risk warning.

Motivation of Earnings Management of *ST SKGF. Firstly, motivation of "Picking stars". After two consecutive years of losses, *ST SKGF was carried out delisting risk warning [6]. It is difficult to solve the crisis of delisting quickly, thus achieving the profit by improving the business performance is a long-term and slow process. In order to achieve the effect of profit and "Picking stars", *ST SKGF choose to whitewash financial statements by earnings management. Secondly, financing motivation. For improving the business performance, *ST SKGF expands the scale of sales and updates production equipment continually to speed up the pace of enterprise transformation. Above a series of economic activities cannot leave the support of amount of capital. However, *ST SKGF facing huge dilemma of financing: the financing way of narrows and difficulties of financing increases because of being implemented delisting risk warning. Thirdly, reward motivation. The annual salary of management is associated with performance of the company, under the system of corporate governance. Managers who are recent departure achieve company agreed managers reward conditions by short-term behavior of earnings management. On the one hand, get higher bonus. On the other hand eliminate the harmful effect of poor performance in last annual report before leaving.

Methods of Earning Management in *ST SKGF. After in-depth research and analysis, this 
paper argues that means of earnings management of *ST SKGF include the following three mainly: use of asset impairment back, related party transactions, non-recurring profit and loss items.

Firstly, use of asset impairment recovery. This article selects annual and semi-annual assets impairment loss amount of *ST SKGF in 2013-2015 and compares the change of the profit comprehensively to highlight asset impairment provision for means of earnings management. Specific value is as follows:

Table 1 Allowances for assets impairment [Yuan] [7]

\begin{tabular}{ccc}
\hline Time & Assets impairment loss amount & Net profit \\
\hline 2015.12 & $-639,285.23$ & $20,865,433.42$ \\
2015.06 & $-1,561,521.42$ & $-16,449,007.19$ \\
2014.12 & $1,555,111.60$ & $-37,684,622.64$ \\
2014.06 & $1,540,480.4$ & $-5,543,405.20$ \\
2013.12 & $568,075.90$ & $-27,393,966.84$ \\
2013.06 & $-931,125.43$ & $-7,111,396.18$ \\
\hline
\end{tabular}

SKGF's losses have been incurred for the latest two years, but allowances for assets impairment was increased in these two years. It would be ready to return for profit. Impairment loss of assets of *ST SKGF in $2015141.11 \%$ percent lower year-on-year mainly, the decline is significant. Description the phenomenon of "Big Amount of Allowances for Assets Impairment Reversal" occur in *ST SKGF. Company profited and created 20865433 Yuan of net income in 2015 which 155.37\% percent higher than the same period in 2014. Company did not disclose the reasons of assets depreciation loss reduce or even negative in 2015. It is the reduction of asset impairment loss amount that promoted the annual profit growth at a certain extent and play the role of the earnings management.

Secondly, sell equity to related party. ${ }^{*}$ ST SKGF transferred it owned $100 \%$ stake in A company to B company and received 129,151,300.00 Yuan as earnings in September 2015 [8]. The company claimed that the transfer price is according to 31 August 2015 net assets value assessment. B company is *ST SKGF's affiliated party and it is controlled by *ST SKGF's Ultimate controlling owners. The sale of the stock realized 41691900.00 Yuan of return which is contributed to the net profit of *ST SKGF accounting for $199.81 \%$ of total net income, increased company's earnings and cash flow, and made up the operating losses for avoiding the company suspended.

As a whole, SKGF's financial position and profitability is still poor, although it striped toxic assets at higher prices with large revenues. ${ }^{*}$ ST SKGF produced -20,086,718.17 Yuan of operating profit in 2015. The company's loss from the main business is still important sector which have a great influence on company's overall business performance. The main profit of *ST SKGF IN 2015 came from the earnings of equity transfer of affiliated parties exchange. Undoubtedly, it is a life-saving straw for *ST SKGF which is on the verge of suspended.

Thirdly, capital lease.*ST SKGF leased factories, factory equipment, office building and related ancillary facilities to the affiliated party C, D company on August 7, 2015 for two years, and the total rent are 48 million Yuan. Details are as follows:

Table 2 Capital lease of *ST SKGF [7]

\begin{tabular}{ccc}
\hline Counterparty & C Company & D Company \\
\hline The amount of leased assets involved & 58014400 Yuan & 106464400 Yuan \\
Rental income & 22080000 Yuan & 25920000 Yuan \\
$\begin{array}{c}\text { Net profit from rent proportion of the } \\
\text { total amount of net profit }\end{array}$ & $105.82 \%$ & $124.22 \%$ \\
\hline
\end{tabular}


Leasing assets transactions between $*$ ST SKGF with related parties got income 48 million Yuan which accounting for $230.04 \%$ of the total amount of net income. Capital lease increased non-operating income of enterprise and enhanced the corporate profitability seemingly. To a great extent, leasing assets transactions avoided the crisis of suspended of *ST SKGF. On the rental market, all kinds of rental cost is difficult to determine, the same assets in the same area of the lease fees may also vary wildly. *ST SKGF carried on the earnings management through "Take Care" of related party rental lease assets to manipulation of the profits by using this loophole.

Lastly, using extraordinary earnings manipulate profits.*ST SKGF used the disposal of non-current assets, government subsidies and other means to manipulate the statements of profit and loss because of a lack of real industrial data to support its statements. The value of *ST SKGF's non-current assets disposal of profits and losses was 41,289,583.02 Yuan in 2015 [9].The figure was up 249.75 percent over 2014. The company did not reveal the reason that variable amplitude anomaly in the annual report clearly. *ST SKGF got huge non-recurring gains and losses and manipulated profit of statements quickly by disposing of fixed assets, intangible assets and other long-term assets at a not fair value. ${ }^{*}$ ST SKGF manipulated profits not only by disposing of non-current assets received surplus but also charging non-financial companies for their capital cost, government subsidies, entrust other investment or assets under management, and other means. Non-recurring gains were 41,329,260.88 Yuan after deducting non-operating expenses. Growth is huger compared with non-recurring gains and losses in 2013 and 2014 which is the reason that *ST SKGF is profitable but deducting non-recurring gains and losses net profit is negative.

Effect of *ST SKGF Earnings Management. The most significant achievements of earnings management for *ST SKGF is withdrew draws delisting risk warning by the Shenzhen stock exchange on 30 March 2016 [9]. The company produced revenue 230,513,610.47 Yuan, net profit $20,865,433.42$ Yuan. It is eligible for cancellation stock delisting risk warning conditions, and the company does not have other situation that needs a delisting warning or other risk warning.

Company management benefits of *ST SKGF have not significant improvement after "Picking stars".*ST SKGF is still substantially loss in 2016. Therefore, earnings management can help enterprises to evade the risk of suspension of listing at a certain extent, but can't improve *ST enterprises' financial condition fundamentally.

\section{Conclusions and Recommendations}

This article analyzed the motivation of earnings management of SKGF which faced risk of delisting from the "stars" and then in-depth analyzed the company's financial data, revealed *ST SKGF how to use asset impairment recovery, related party transactions, and non-recurring profit and loss and other means for earnings management to success to protect shell.

*ST SKGF is not an exception. The phenomenon of *ST companies earnings management is common. The emergence of the phenomenon is a result of several factors, including *ST delisting system, audit quality, relevant policies, etc. So we should regulation and governance the behavior of earnings management from the following several aspects [10].

Improve the System of *ST Delisting. Delisting system should limit the proportion of *ST companies non-recurring profit and loss accounts for the companies' net profit, increase the operating profit and set a minimum percentage to measures *ST companies shall be delisted for avoiding $*$ ST companies relying too much on non-operating income. In addition, the delisting system also should conduct a comprehensive consideration combined with *ST's market prospect and the capability of continuing operations.

Strengthen the Information Disclosure Regulation of *ST Companies. Regulatory guidelines should make clear the specific regulatory standards about how to disclosure matters that influence the profit and loss, or have a big impact on *ST companies include time, content, way and so on in order to avoid *ST companies use by fuzzy area on earnings management. Related departments should mobilize the public and the media supervision power and let more social forces to join in supervision, intensify in violation of the rules is punished at the same time.

Improve the Audit Quality of *ST Companies. Improving the quality of external audit should 
strengthen the management of accounting firms and independence of audit. Increasing audit cost of negligence to reduce the possibility of audit personnel and institutions to shield earnings management behavior of $*$ ST companies is very important too.

\section{References}

[1] C Cai, M Li and H He: Accounting Study, (2013) No.10, p.35-42. (In Chinese)

[2] T Lu, and D.X Zhang: Accounting Study, (2014) No.01, p.35-41. (In Chinese)

[3] H.X Wang, L Yang and X.F Wang: Friends of Accounting, (2014) No.4, p.85-87. (In Chinese)

[4] J.W Lu and W.W Ma: Journal of Shanxi Finance and Economics University, (2015) No.5, p.113-124. (In Chinese)

[5] J. Ronen and V. Yaari. Accounting Review, (2011) No.115, p.40-44.

[6] K. Gunny. Contemporary Accounting Research, Vol. 27, (2010) No. 03, p.855-888.

[7] http://www.eastmoney.com/

[8] http://www.cninfo.com.cn/cninfo-new/index

[9] http://quote.eastmoney.com/sz002633.html?

[10]X.D Liu. The Research on Earning Management used by Listed Company to Flee From Special Treatment -With ST SHANXI COKING as an example Southwestern (Ph. D University of Finance and Economics, China 2012) p.30. (In Chinese) 